\section{Plans for Mars} impress

Washington

THE embattled US space programme seems to be losing ground yet again, judging by a recent announcement of Soviet intentions. At the International Conference on Solar System exploration, Pasadena, California, senior Soviet scientists described ambitious (but so far unapproved) plans to launch a comprehensive exploration of Mars during the 1990s.

Four missions are on the drawing board: a balloon explorer, a rover, a lander and sampler, and a retrieval mission. Each launch would have an identical

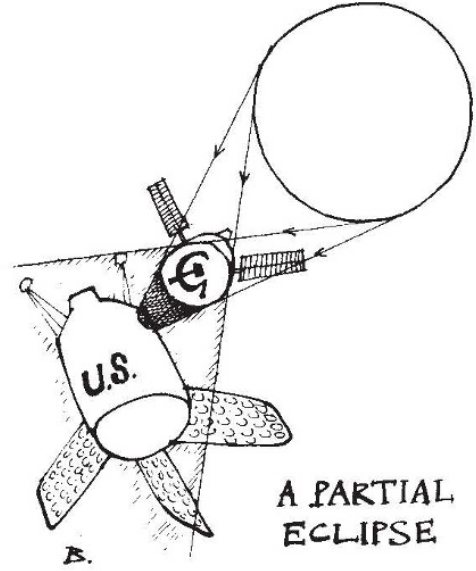

backup, making necessary a total of eight launches on the large Proton rocket. These proposals are still under detailed review, and have yet to be formally presented to the Soviet government, but Soviet scientists are apparently confident that at least some parts of the programme will leave the ground. The balloon mission, which may include a small rover, could be sent off as early as 1992 .

US scientists at the meeting were clearly impressed, not only by what the Soviets revealed of their long-term thinking but also by the fact that they revealed it at all.

The contrast in the level of optimism of US and Soviet space scientists showed up at a meeting of the National Aeronautics and Space Administration (NASA) in Washington last week, where a large committee met to find ways of revitalizing NASA's overall goals. The key words were 'augmentation' and 'leverage' which, in combination, seem to mean trying to add to existing plans in inexpensive but visibly productive ways. The committee expressed its pleasure that the collaboration agreement signed in Moscow earlier this year enabled NASA to gain control over the entrepreneurial spirit behind recent US-Soviet projects. Any US collaboration with the Soviets on the latest Mars ventures would have to be negotiated through high-level meetings.

David Lindley

\title{
California introduces methanol for cars in pollution fight
}

\section{San Francisco}

If California were a nation, it would be the world's third largest consumer of gasoline (motor fuel), after the United States and the Soviet Union. No wonder, then, that it has been a leader in fighting air pollution and, with 22 million automobiles, has enacted tougher autoemission regulations than the US Federal Environmental Protection Agency. The latest plan, which may set trends for the rest of the world, is to introduce methanol as an alternative to gasoline.

Under a scheme announced last week, the California Energy Commission and ARCO Corporation, the state's largest gasoline retailer, agreed to begin selling methanol at 25 southern California stations by the end of next year. A similar commitment for northern California is expected from Chevron USA Inc. The state will help things along by buying 5,000 government cars that can run on either gasoline or methanol, according to the California Energy Commission. If Californians follow this lead, the commission hopes $10-15$ per cent of vehicles within the state will use methanol within a decade.

Methanol's biggest advantage is that it produces half the oxidants and particulates of gasoline. And it is easy to make from coal and natural gas which the United States has in abundance. Most US automobile manufacturers are developing flexible-fuel cars that can use either methanol or gasoline in the same tank, and they are not expected to cost much more than conventional cars. The only problem is that methanol produces three times as much formaldehyde, a potential carcinogen, as gasoline. But it is not technically difficult to design a converter that turns formaldehyde emission to water vapour and carbon dioxide. Marcia Barinaga - Britain, France and Italy are close to agreement on limits for car exhaust emissions. The European Economic Community (EEC) proposed complex regulations two years ago to limit emissions of hydrocarbons, sulphur and nitrogen oxides. Member states have been arguing since then, with motor-manufacturing nations seeking compromises on standards and timing; meanwhile, West Germany and the Netherlands have already implemented the regulations. Under the EEC timetable, all small and medium-sized cars would have to conform to the new standards in stages by October 1991. The UK government is still resisting a proposal on large cars which would involve catalytic converters.
Kathy Johnston

\section{Solidarity physicist is unable to gain scientific employment}

London

DR Andrzej Jurewicz, a leading Polish particle physicist and a former Solidarity activist, has now been without a job for four years, according to a recent newsletter of the unofficial Polish "Social Committee for Science" (SKN). This committee, whose membership is not announced but which is believed to include several members of the Polish Academy of Sciences, acts as a human rights watchdog for the scientific professions, as well as sponsoring bursaries for scholars unable to complete their research within the official scientific establishment.

Jurewicz formerly worked at the Institute of Nuclear Research at Swierk, outside Warsaw, where he headed the particle physics group, and, during 198081 , was head of the working party for scientific affairs in the institute's Solidarity chapter. At the end of 1982, the institute was 'reorganized' into three smaller institutes, and as a result the authorities were able to dismiss known Solidarity supporters without contravening Poland's new labour laws. Valuable research was thus abruptly terminated, and the dismissals were crudely carried out, with those dismissed being refused entry to the institute either to clear their desks or to collect their severance pay (see Nature 303, 565; 1983).

Shortly before the "reorganization" of the institute, Jurewicz had been recommended by his colleagues for a full professorship. Since 1 May 1983, Jurewicz has been officially "at the disposal of the State Atomic Energy Agency", but has been consistently blocked from obtaining a post either in the agency or otherwise. During the past four years he has been employed for just four months.

Jurewicz is now the only former member of the Department of Theoretical Nuclear Physics at the disbanded institute not to have been given scientific employment. He has attempted to bring a case through the Labour Court, but on 30 April 1986 the court rejected his plea and sent the files on his case to the PAA for consideration. So far, said the SKN, in its "Information Service" bulletin dated 5 April 1987, "the president of the agency has not replied". 